\title{
Teachers' digital competences in the first educational policy responses to the COVID-19 crisis in four countries
}

\author{
Mihaela Mitescu-Manea`, Leyla Safta-Zecheria •, Eszter Neumann •, Valentina \\ Bodrug-Lungu ', Valentina Milenkova`, Vladislava Lendzhova`
}

\begin{abstract}
With the sudden widespread closure of schools since February-March 2020 due to the physical distancing measures associated with the COVID-19 pandemic, the digital competences became a focus of attention, being of central importance to the swift and equitable transition to the various forms of emergency remote teaching implemented throughout the world as a strategy to insure continuity in education. This almost instantaneous mass shift to teaching online has made transparent great disparities in how digital competences - particularly those of teachers - were conceptualized, taught and assessed within various educational programs. We present a comparative analysis of the approaches to teachers' learning and professional development that state and non-state actors in four Central and East European countries have articulated in the first months of COVID-19 related lockdown. We take a Critical Frame Analysis approach to exploring the roles played by state and non-state actors in the four countries in conceptually framing the relationship between the digital competences required in emergency remote teaching and teachers' learning and professional development at the beginning of the COVID-19 crisis. It is suggested that the educational policy debate at the beginning of the crisis rendered visible: a) that this massive sudden shift required understanding digitalization as a complex multifaceted process requiring levels of digital and pedagogical competence teachers were unlikely to have previously developed; b) that addressing these issues through short-term interventions would only exacerbate the risk of ignoring arising equity issues; c) that situating emergency measures in the context of potential medium and long-term developments could open opportunities to explore mainstreaming the digitalization of education and promoting blended learning, as well as offer a better perspective on issues of digital poverty and the inequitable impact of not addressing it adequately will have in the future.
\end{abstract}

Keywords: digital competences, teachers' learning and professional development, emergency remote teaching.

\footnotetext{
- PhD, Lecturer at the Department of Education, West University of Timisoara, Romania, mihaela.mitescu@e-uvt.ro

- PhD, Postdoctoral Research Assistant at the Department of Education, West University of Timisoara, Romania, leyla.safta@e-uvt.ro

- PhD, Research Fellow at the Centre for Social Sciences - MTA Centre of Excellence, Hungary, neumann.eszter@tk.mta.hu

- PhD, Associate Professor at the Moldova State University, Chisinau, Republic of Moldova, valbodrug@mail.ru

- Professor at the Department of Sociology, South-West University “Neofit Rilski”, Bulgaria, vmilenkova@gmail.com

- PhD, Assistant Professor at the Department of Sociology, South-West University "Neofit Rilski", Bulgaria, vlendzhova@gmail.com
} 


\section{Introduction}

At stage one of the COVID-19 pandemic outburst, with the closure of schools, policy makers were faced with two main challenges: first, ensuring the learning needs of students from all socio-economic backgrounds, but especially for those from vulnerable backgrounds; second, providing systemic responses for the long-term educational, social and economic challenges generated by the pandemic (Van Lancker and Parolin, 2020). This twofold challenge prompted a global haste to produce the fastest and most fitting policy responses to ensure safety and continuity of educational provision.

Originally addressing the shift away from face-to-face activities at university due to the continuously extending period of social distancing and lockdown measures since early March 2020, the term 'emergency remote teaching' coined by Hodges and collaborators (2020), took over the language of transitions in educational provision associated with the Covid-19 pandemic. Educationalists everywhere have quickly picked up on the notion of 'emergency remote teaching' (Hodges et al, 2020), if merely to stress that the [Covid-19 pandemic] imposed 'rushed activities [which] should not be equated with e-learning, distance learning or another form of carefully planned and administered online learning experience' (Kerres, 2020: 692).

Whilst the impending educational shifts might have been rooted in the best of intentions (Aguilera and Nightingale-Lee, 2020), it almost immediately and quasiubiquitously became apparent that it raised significant challenges on various organizational, pedagogical and ethical aspects. The four countries where our analytical focus is located, namely: Romania, Hungary, Bulgaria and Republic of Moldova, were no exception. The shift to emergency remote teaching meant facing, almost overnight, the challenge of assessing and developing an adequate infrastructure of educational technology making possible whichever chosen continuation strategy.

Worldwide, this challenge impacted educational systems and organizations in the most diverse ways, ranging from either expanding the use of well-articulated infrastructure already in place and use (Scull et al,2020), to having to invest for the first time in educational technologies making remote teaching possible (Hodges et a, 2020), either facing traditional cultural resistances to the widespread use of technology for educational purposes (Kerres, 2020), or the lack of funding immediately available (OECD, 2018; Di Pietro et al, 2020), and great socio-economic disparities affecting students, parents and families living in historically marginalized communities the most (Aguilera and Nightingale-Lee, 2020). Eurostat data from 2019 indicates that access to broadband internet connection varies greatly by household income across all European countries, and that cross-country variability is much larger in the bottom quartile, with the percentage of households with broadband internet connection in the lowest income quartile varying between less than $40 \%$ in Bulgaria as opposed to more than $90 \%$ in the Netherlands (Di Pietro et al, 2020). Closely connected to technological and digital 
infrastructure disparities, digital competences and capabilities of adults and caregivers suddenly being appointed responsibility to mediate their children's access to classes and other school related activities online (in the context of newly imposed continuation measures requiring educational activities be transferred online) were among the most significant factors impacting the risk of exacerbating educational inequities. Parental education appears to be positively correlated to children's access to computer possession at home, differences between high and low skilled parents being especially significant in Romania, Bulgaria and Hungary amongst other countries (OECD, 2019).

Aimed at preventing students from missing out whilst away from schools, initiatives promoting the continuation of school activities remotely, particularly those involving digitalization, raised questions concerning teachers' digital competence and content pedagogical knowledge (Schulmann, 1987) needed for teaching online (Rapanta et al, 2020; Ching, Su and Baldwin, 2018), either addressing implications for initial teacher education (Scull et al, 2020; Dyment and Downing, 2020), or continuing teacher learning and professional development (König et al, 2020; Carillo and Assunção-Flores, 2020). The general situation was quite diverse in terms of national systems' preparedness to orchestrate efficient support for teachers' learning and professional development. The almost instantaneous mass shift to teaching online has made transparent great disparities in how digital competences - particularly those of teachers - were conceptualized, taught and assessed within various educational programs (Reimers and Schleicher, 2020). In international comparisons, some countries appeared to have more problems than others in insuring a smooth and efficient transition to online education, particularly when uneven distributions of access to internet across rural and urban areas and of software available in schools, coupled with lower levels of digital skills - especially those of teachers (Holotescu et al, 2020).

Here we present a comparative analysis of the approaches to teachers' learning and professional development that state and non-state actors in four Central and East European countries, namely Romania, Hungary, Bulgaria and Republic of Moldova, have proposed in the first months of COVID-19 lockdown.

\section{Methodology}

The data, findings and discussions presented here are part of a larger study designed as a cross-national comparative analysis of the policy responses to the crisis of the COVID19 pandemic during the state of emergency and general lockdown between March and June 2020. In the extended comparative analysis our main focus was on exploring the discursive power dynamics connected to policy making (Verloo, 2005) in the four countries, during the early stages of the COVID-19 crisis in CEE region, seeking to form a contextualized understanding of the political and systemic triggers of inequity in education.

The goal of the analysis proposed here is to explore the specific relationship between approaches to teachers' learning and professional development and the ways in which 
teachers' digital competences were addressed in the policy debates in the four countries. To this avail we specifically address the following research question: How have digital competences and teachers' learning and professional development been addressed in the first educational policy responses to COVID-19 in Hungary, Romania, Bulgaria and Republic of Moldova?

In our comparative analysis of the educational policy responses in the four countries, we operationalized this aspect of inquiry on two specific coordinates, seeking to form a deeper understanding first of how teachers' learning and professional development reflected in the policy debates by looking at its specific focus, who was addressing it, to what end and questioning what the proposed provision strategy was; then, we inquired over how digital competences were conceptualized, whose digital competence have policy debates addressed, and to whom was responsibility for action assigned to in addressing issues of digital competences.

\section{Research design}

In order to capture comparatively the ways in which the first policy responses in the four countries addressed teachers' professional learning and development in relation to issues of digital competence, we employed an adapted version of CFA (Dombos et al, 2012). CFA concentrates on identifying policy frames which function as an organizing principle that transform fragmentary or incidental information into a structured and meaningful problem, in which a solution is implicitly or explicitly included (Verloo, 2005).

\section{Data sampling and collection}

The data collected and analysed in this cross-national comparative study consists of educational policy documents, including policy statements by non-governmental actors issued in the period between mid-March and mid-May 2020 in the four countries.

Documents issued by the following categories of actors were sampled: international organizations/supranational bodies (where relevant), governmental bodies, NGOs, and experts.

Our data selection followed two steps: a) identifying state policy documents and policy related statements issued outside the state apparatus (i.e. by NGOs, stakeholders and experts) addressing education in the four countries during the lockdown and state of emergency period, with a specific focus on explicitly/implicitly addressing inequity issues and b) narrowing our selection to the texts which made it to the flow of open data resources, therefore could be considered potentially referential to other voices engaging in the policy discourse at the time of the pandemic. We did not limit the number of documents sampled within types or issues. For the purposes of this specific analysis, the sampling process in the four countries followed the principle of saturation within the national samples considering: a) the specific timeframe; b) relevance to issues of digital 
competence and teachers' learning and professional development; c) the potential of creating authority by means of influencing the mainstream policy discourse.

In the broader comparative analysis exploring inequity issues in the first educational policy responses to the COVID-19 crisis, we conducted open sampling and then categorized the documents in six story-grammars: inequities in educational provision, access, educational technology, curriculum, digital competence, teachers' learning and professional development. We have made the necessary adaptive changes to the CFA methodology to render it operational in a context of crisis, characterized by a condensation of statements from policy relevant actors that needed to be processed quickly.

We constructed issue-histories (Dombos et al. 2012) in each country: we created detailed chronological listings of policy developments in the proposed time frame in each country, as well as texts that framed the policy debate in education before the beginning of the pandemic crisis and could be traced in relevance to the issues on the educational policy responses to the pandemic crises' agenda. Our final sample included 68 policy documents: 21 for Romania, 21 for Hungary, 15 for Bulgaria and 11 for the Republic of Moldova.

Out of this general pool of national policy documents and texts we initially sampled, in line with the scope of analysis presented here, we are selectively looking at the texts that were relevant to understanding the ways in which the first policy responses in the four countries addressed teachers' professional learning and development in relation to issues of digital competence.

\section{Coding and Analysis}

Sets of syntactic relations characteristic of statements in a particular genre of texts (Dombos et al, 2012, p. 10) served as a way of setting the format of coding in advance (standardizing) per each general category: digital competence and teachers' learning and professional development. These syntactic relations were structured as story-grammars, allowing for an organization of the codes researchers produced in the open coding of data that made comparison possible at issue-frame level. The story-grammars were discussed in detail by the team of researchers at the beginning and throughout the first phase of analysis when the documents were coded for content in the national sets of data. Adjustments were permitted, the researchers being advised to call for a group discussion of the proposed changes whilst progressing with coding and analysis of data at national level.

Following coding and code standardization the next step was to construct issue frames. The frame construction started from identifying the marker fields - fields that marked the difference between the frames (Dombos et al, 2012). The marker fields in our coding of the six story-grammars, which were especially helpful in identifying issue frames were actor categories (who authored the text, who is nominated in it), document 
genre (i.e. decree, resolution, civil society text, etc.) and modality (i.e. agenda-setting, contesting, regulative, delegating, proposing alternatives), key points (content), related issues (i.e. access, provision, educational technology, curriculum etc.), and descriptive/normative features (i.e. creating authority, practical, problem/solution oriented, targeted). In the second phase of analysis, issue-frames identified in the coding of story-grammars at national level were discussed.

\section{Findings discussed}

\section{Teachers' digital competences}

Table 1 presents the documents sampled in the extended comparative study for each of the six story-grammars at national level, and indicates the categories of actors (state/non-state actors) who have articulated issues of inequity within each storygrammar, in each country in our analysis. Our national samples of policy documents and texts have been structured to facilitate an ample analytical scope through the six-story grammars, yet for the purposes of this analysis we will focus particularly on the findings on two specific topics: digital competence and teachers' learning and professional development. In Table 1 these two story grammars appear in highlight.

Table 1 The number of documents sampled per story-grammar, engaging either state or non-state actors, in each of the four national contexts, at the onset of the COVID-19 pandemic

\begin{tabular}{|c|c|c|c|c|c|c|c|c|}
\hline \multirow{3}{*}{ Story grammar } & \multicolumn{2}{|c|}{ Romania } & \multicolumn{2}{|c|}{ Hungary } & \multicolumn{2}{|c|}{$\begin{array}{l}\text { Republic of } \\
\text { Moldova }\end{array}$} & \multicolumn{2}{|c|}{ Bulgaria } \\
\hline & \multicolumn{8}{|c|}{ Sample size/actor category/story-grammar } \\
\hline & $\begin{array}{l}\text { State } \\
\text { actors }\end{array}$ & $\begin{array}{l}\text { Non- } \\
\text { state } \\
\text { actors }\end{array}$ & $\begin{array}{l}\text { State } \\
\text { actors }\end{array}$ & $\begin{array}{l}\text { Non- } \\
\text { state } \\
\text { actors }\end{array}$ & $\begin{array}{l}\text { State } \\
\text { actors }\end{array}$ & $\begin{array}{l}\text { Non- } \\
\text { state } \\
\text { actors }\end{array}$ & $\begin{array}{l}\text { State } \\
\text { actors }\end{array}$ & $\begin{array}{l}\text { Non- } \\
\text { state } \\
\text { actors }\end{array}$ \\
\hline Provision & 2 & 14 & 6 & 3 & 3 & 5 & 7 & 5 \\
\hline Access & 6 & 12 & 7 & 6 & 2 & 5 & 8 & 6 \\
\hline $\begin{array}{l}\text { Educational } \\
\text { Technology }\end{array}$ & 1 & 3 & 1 & 3 & 1 & 5 & 4 & 4 \\
\hline $\begin{array}{l}\text { Digital } \\
\text { competence }\end{array}$ & 1 & 2 & 1 & - & 1 & 5 & 4 & 3 \\
\hline Curriculum & 3 & 9 & 1 & - & 2 & 4 & 6 & 3 \\
\hline $\begin{array}{l}\text { Teachers } \\
\text { learning and } \\
\text { professional } \\
\text { development }\end{array}$ & 1 & 5 & 3 & 3 & 1 & 2 & 7 & 3 \\
\hline $\begin{array}{l}\text { Total National } \\
\text { Sample size }\end{array}$ & & 1 & & & & 1 & & \\
\hline
\end{tabular}


The shift to online teaching prompted a general call in all four countries for implementing or improving and expanding existing digital infrastructure and available educational technology. The uneven distribution of technological means and infrastructure along the socio-economical and residential characteristics of the student populations (in all four countries) and the inadequacy of available educational technology to the educational needs of various age and ability categories of students (i.e. SEND/ special educational needs students in Hungary, pre-schoolers in Romania, Roma or other minority language speaking students in Romania and Bulgaria) were among the most significant topics marking the policy debate at the onset of the COVID-19 pandemic. Particularly non-governmental actors in the four countries were quick to remind state actors of the danger of further exacerbating social and educational inequities by ignoring evidence of technological disparities emphasized in internationally produced data preexisting the COVID-19 crisis, such as reports by OECD or Eurostat in 2019 and the years before that (OECD, 2019, 2020; Eurostat, 2019).

In the context of setting up emergency remote teaching as a strategy to insure continuity to educational activities within the different national contexts, digital competence was generally conceptualized as the ability to use available digital technology for educational purposes (teaching, learning and assessment). It became visible in close proximity to discussing learning goals and assigning teaching and learning roles to teachers, students and parents in the context of shifting to online education. The development of students' or parents' digital competences was generally not addressed by the state actors, the lack of educational provision in this respect being noted by nongovernmental actors in Romania. In Hungary, non-governmental actors explicitly focused on the digital transition of teachers, students and parents with digital skills and teaching materials.

\section{Opportunities for teacher's learning and professional development}

The strategies to operationalize teachers' learning and development of digital competences varied from recommended e-learning platforms and digital resources to be used by teachers for learning purposes (Romania and Hungary), to self-guided learning (Moldova), sharing best practices in online professional groups and programs organized by traditional providers of professional development in each country (all four countries). However, access to the proposed learning and professional development opportunities was not equal, certain professional categories' learning needs (i.e. higher upper secondary teachers in Romania) not being addressed at all, thus raising educational equity issues.

Table 2 presents an overall image of the approaches state and non-state actors in the four countries have proposed in the first months of COVID-19 lockdown, for setting up 
support for teachers' learning and professional development and the ways in which their specific proposals presented the different aspects of digital competence being prioritized.

Table 2. Teachers' learning and professional development \& approaches to Digital competences prioritized in the first policy responses to COVID-19 by state and non-state actors in the four countries

\begin{tabular}{|c|c|c|c|c|c|c|c|c|c|}
\hline \multirow{3}{*}{$\begin{array}{l} \\
\text { Teachers' } \\
\text { learning and } \\
\text { professional } \\
\text { developme } \\
\text { nt (TLPD) }\end{array}$} & & \multicolumn{2}{|c|}{ Romania } & \multicolumn{2}{|c|}{ Hungary } & \multicolumn{2}{|c|}{$\begin{array}{l}\text { Republic of } \\
\text { Moldova }\end{array}$} & \multicolumn{2}{|c|}{ Bulgaria } \\
\hline & & \multicolumn{8}{|c|}{$\begin{array}{l}\text { Sample indicating Actor category } \\
\text { problem/proposing /advancing action }\end{array}$} \\
\hline & & $\begin{array}{l}\text { State } \\
\text { actors }\end{array}$ & $\begin{array}{l}\text { Non- } \\
\text { state } \\
\text { actors }\end{array}$ & $\begin{array}{l}\text { State } \\
\text { actors }\end{array}$ & $\begin{array}{l}\text { Non- } \\
\text { state } \\
\text { actors }\end{array}$ & $\begin{array}{l}\text { State } \\
\text { actors }\end{array}$ & $\begin{array}{l}\text { Non- } \\
\text { state } \\
\text { actors }\end{array}$ & $\begin{array}{l}\text { State } \\
\text { actors }\end{array}$ & $\begin{array}{l}\text { Non- } \\
\text { state } \\
\text { actors }\end{array}$ \\
\hline & $\begin{array}{l}\text { Mentoring } \\
\text { teachers } \\
\text { (mentors from } \\
\text { programs of } \\
\text { TLPD for digital } \\
\text { competence, } \\
\text { running before } \\
\text { the COVID-19 } \\
\text { Pandemic) }\end{array}$ & 1 & 1 & 1 & & & & & \\
\hline & $\begin{array}{l}\text { Online } \\
\text { repositories and } \\
\text { collections of } \\
\text { teaching } \\
\text { materials }\end{array}$ & 1 & & 1 & 1 & 1 & & 1 & \\
\hline & $\begin{array}{l}\text { Access to online } \\
\text { courses, and } \\
\text { teaching } \\
\text { platforms, apps }\end{array}$ & 1 & & 1 & 1 & & 1 & 1 & \\
\hline & $\begin{array}{l}\text { Teachers' sharing } \\
\text { best-practices } \\
\text { online }\end{array}$ & 1 & & & & & 1 & & \\
\hline & $\begin{array}{l}\text { Support } \\
\text { networks for } \\
\text { schools }\end{array}$ & & 1 & & 1 & & 1 & & \\
\hline & $\begin{array}{l}\text { Support and } \\
\text { recommendation } \\
\mathrm{s} \text { for SEND/ } \\
\text { minority groups }\end{array}$ & & 1 & 1 & 1 & & & 1 & 1 \\
\hline \multirow[t]{2}{*}{$\begin{array}{l}\text { Specific } \\
\text { Emphasis on } \\
\text { Teachers' } \\
\text { Digital } \\
\text { competence }\end{array}$} & $\begin{array}{l}\text { Short-Term - } \\
\text { instrumental to } \\
\text { emergency } \\
\text { remote teaching }\end{array}$ & 1 & & 1 & 1 & 1 & & 1 & \\
\hline & $\begin{array}{l}\text { Medium \& Long } \\
\text { Term - overall } \\
\text { development of } \\
\text { digital } \\
\text { competences for } \\
\text { teaching and } \\
\text { learning }\end{array}$ & & 2 & & 1 & & 2 & & \\
\hline
\end{tabular}


As Table 2 indicates, state actors in Hungary and in Romania advanced the idea of using existing programs or policies (i.e. the CRED programme in Romania, or the National Digital Education Strategy in Hungary) to harbour large scale mentoring opportunities, whereby experts or teachers who were previously trained on ICT and related skills for teaching could provide mentoring on digital methodologies for education to teachers who have not yet acquired these skills, at the onset of the COVID-19 pandemic:

Based on the prior assessment of needs, schools within the range of their infrastructural possibilities can help students and families by lending tools. (...) It is advisable to assign a technical team of teachers/special educators who work as the institutional helpdesk and support specialists. If this is not possible in the school, it is useful to involve parents or to seek civic initiatives which connect specialists with the schools in need. (Hungarian state actor)

However optimistic and reassuring the state actors in Hungary were, what was missing from the picture was that the country's digital education strategy ratified by the parliament in 2016 was only partially realized, most importantly the digitalization of schools and the competence development of teachers having been left far behind the planned schedule. Nevertheless, having had appointed an office at the Ministry for Innovation and Technology dedicated to this programme allowed the Hungarian state to assign some responsibilities to it, as an immediate response to the COVID-19 crisis, which became apparent in the policy documents we have analysed. Whilst state actors would thus far claim teachers and schools are well prepared, and even more so, it is thriving in the context of emergency remote teaching, non-state actors highlighted that the reality contradicts by large the image state actors put forth, and there are huge disparities across the education system in the schools' infrastructural and professional readiness to shift to online teaching methods.

In Romania, non-state actors were quick to notice that state's recommendations in this respect were lacking relevance for the teaching requirements of certain age groups (i.e. upper higher secondary students). They also noted that independently conducted inquiries and analyses of the teachers' levels of confidence and familiarity with digital technologies and methodologies for teaching online were less than optimistic. Furthermore, the state's postponement of publicizing a national strategy for emergency remote teaching for almost one month after declaring the state of emergency and national lockdown, coupled with the realization that prior to the COVID-19 crisis merely $4 \%$ of the teachers in the country had been included in professional development programs addressing ICT and digital competences were promptly criticized straight from the beginning of the first educational policy responses to the COVID-19 crisis:

\footnotetext{
The level of digital competence of teachers in secondary education cannot be assessed; only $4 \%$ of the in-service professional development programs implemented by the CCD in 20132018 aimed at developing digital competences related to teaching, learning and assessing. (Romanian non-state actor)
}

Another prominent aspect readily observable in Table 2 is that in all four countries the states had provided online repositories of recommendations, best practice examples and curated digital teaching tools as a fast (and rather short-term) response to the 
teachers' needs in the course of setting up and delivering online teaching. In doing so, non-state actors (i.e. multinational and national companies) have partnered with the states to ensure online resources for education were free of charge. Except in Moldova, state actors in all other countries have also recommended freely accessible online courses and tutorials for accessing different digital platforms suitable for emergency remote teaching. Overall, state-actors in all four countries have mainly focused on addressing teachers' learning and professional development on a short-term timespan, building on a rhetoric of immediate responses to a major crisis and on doing everything possible to contain its' potential negative effects on health and education.

In addition to expressing opposition and contestation to the states' approaches to teachers' learning and professional development needs related to the digital competences required in rendering operational emergency remote teaching, non-state actors - especially those in Romania and Moldova - have also had in common expressing prospective positions over the medium and long-term implications of teachers' learning and professional development addressing digital competences. In doing so, they have also shifted the conceptual perspective over digital competences for teaching - by expanding its' approach in the policy debates at the beginning of the COVID-19 crisis to incorporate capabilities beyond the technical and instrumental aspects of learning to use certain digital tools, or to copy ways of doing exemplified in best-practice models. This conceptual expansion implied creative and reflective capabilities associated with digital competences were implying wider, more complex horizons of pedagogical responsibility. Such were those implied in the Romanian non-state actors' proposal to prospect the possibility of using the crisis as an opportunity to revisit the educational resources of blended and hybrid learning in the long-term perspective of educational reforms:

One model successfully implemented in other European systems is blended learning which combines traditional and digital teaching. This model ensures not only fruition of the potential of digital resources, but the resilience of the learning processes in the face of crises such as this one, as well as improving educational standards by providing best-practice elessons to all children. (Romanian non-state actor)

The same was visible in the Moldovan non-state actors' call for national strategies addressing continuous development of digital competences for teachers and school managers.

In the perspective of prolonging the state of emergency, it is necessary to develop curricula and educational content using e-learning principles. (Moldovan non-state actor)

In terms of policy-making during the pandemic, our data sets in the four national contexts indicate that the agenda-setting role was played by the government. However, government documents predominantly served a regulative and delegative purpose. Other actors typically reacted to these actions either by expressing discontent and contestation (i.e advocacy NGOs, Teacher Unions, Student Councils), offering support for the government in tackling the crisis (corporations, international organizations), 
expressing contestation and proposing policy alternatives (Unions, advocacy NGOs, experts), proposing targeted best practices (specialized advocacy NGOs); or setting up non-governmental services to address the lack of government provision and setting the agenda by taking action that addresses government failures (NGOs addressing digital poverty and providing digital support).

Teachers' learning opportunities targeting the development of their digital competences were topics in the policy debate mainly framed by concerns related to digital poverty in the four countries and by calls to explore the crisis as an opportunity for change and improvement in education. Both these frames were dominantly articulated by non-governmental actors. The concerns addressing issues of digital poverty indicated that disadvantaged communities were being excluded from online teaching (due to lack of stable internet connection, digital proficiency, etc.) and that their educational disadvantage was likely to exacerbate as a result of the crisis. This issue was neither recognized, nor addressed by the state.

For example, in Hungary, state documents exclusively expressed that schools can lend equipment to families (within a contractual format), or students can use school facilities, but did not go into details about the challenges of those who did not have access to online learning from home and how this could be mitigated by state measures. In Romania state documents advanced a national strategy set up as an intervention national plan for ceasing all face to face educational activities and shifting to online, but failed to identify the problem and address the needs of students who are unable to use age and ability appropriate educational technologies, or do not have access to electrical energy. A similar situation could be documented in Moldova and Bulgaria.

\section{[The Covid 19 pandemic] Crisis as an opportunity}

Oftentimes in the policy debates at the beginning of the COVID-19 crisis, general concerns addressing digital poverty issues prompted other, more specific issue frames, as was that of addressing the technological, methodological and learning support for actors in education, involving the transfer of digital competences to teachers, pupils, parents, etc. The improvement of digitalization and of digital competences was more of a prognostic frame in the policy debate at the beginning of the COVID-19 crisis, involving medium and/or long-term solutions based on blended learning, and on adapting the curricula and the teaching methodologies to fit the requirements and principles of online pedagogy. Yet, despite state actors recognizing digitalization involved rather pedagogically complex processes, emphasis was placed on the importance of schools rendering it operational and functional within a short-term horizon of action. This has prompted non-state actors to voice concerns over the state actors' disregard of digitalization as a complex process going beyond access to technology and involving a proper diagnosis of the actual digital competences and knowledge of online pedagogy professionals in education could realistically demonstrate in their current professional practice. 
The idea of using the crisis as an opportunity for improving access to and provision of education, and for developing digital competences in education was generally missing from state communication in the four countries at the beginning of the COVID-19 pandemic. It was, however, an idea put forth by non-state actors in Romania, emphasizing the medium and long-term horizons for possible action on digitalization in education.

When state actors in Hungary did touch the idea, it was treated in state communication completely independent from the issue of digital poverty:

\footnotetext{
Hungarian public education as a whole is going through unusual times due to the coronavirus pandemic. Almost all involved in the sector agree that the digital work scheme which was introduced as a necessity holds possibilities alongside difficulties: addressing it suitably could mean a great step towards more knowledge and broader spread of digital methods and contents. (Hungarian state actor)
}

The rhetoric of state communication was more imbued with defensive tones, building on the idea of short-term measures, containing the negative effects of a major, unprecedented crisis, than on prospective thinking, taking the COVID-19 early stages of the crisis as a point of departure for medium and long-term educational reforms. None of the state documents we have analysed has employed this specific issue-frame.

Another clear pattern can be noted in the discursive dynamics between state and non-state actors. State and non-state actors find themselves in a role-assigning and agenda-setting exchange. This exchange is marked by two co-constitutive dynamics: (1) state actors delegate and diffuse responsibilities to other actors and (2) non-state actors operate discursively through contesting the actions of state/ governmental actors. (1) The first dynamic is visible in legislative documents typically taking on roles of control and monitoring, whilst assigning implementation responsibilities to teachers and schools, with little reference (i.e. a general endorsement of a digital platform to be used as reference point for teaching and learning resources for all age groups and all subjects), or no reference at all - i.e. in regard of inclusive education, particular age groups, or newly appointed responsible educational agents, such as parents - to the support and guidance teachers and schools might need to produce the required responses. (2) The second dynamic is visible in documents of contesting modality, issued by unions and advocacy NGOs assigning responsibility to the state to provide means of access to digital teaching and mitigate inequalities generated by unequal access to online teaching. State communication is defensive in the sense that it emphasises that emergency measures and not long-term policy strategy is being implemented.

\section{Conclusion}

In the comparative analysis presented here we have used the CFA approach to understand how digital competences and teachers' learning and professional development have been addressed in the first education policy responses to the COVID19 crisis in four Central and East-European countries. 
Despite efforts to support remote learning, the efficiency of digitalized educational provision in the four countries at the beginning of the COVID-19 crisis was limited due to the lack of and/ or inadequacy of internet connection and digital devices to facilitate online learning. Educational inequities were likely to be exacerbated by great disparities in the level of digital competence of teachers, students and supporting family members.

The initial educational policy responses to the first wave of the Covid-19 pandemic involved an unprecedented shift towards online teaching and learning that took the form of emergency remote education. Both state and non-state actors in CEE recognized that this massive sudden shift required understanding digitalization as a complex multifaceted process, as well as required from teachers, digital competences that they were unlikely to have previously developed to a sufficient extent for successful educational provision. State actors addressed these issues through short-term interventions (such as providing teachers with repositories and best practice examples) and implemented these unequally, ignoring arising equity issues (e.g. in Romania, the needs of upper-secondary teachers remained unaddressed in official government promoted repositories for online teaching). Non-state actors placed emergency measures in the context of medium and long-term developments focusing on both the present crisis as an opportunity to mainstream the digitalization of education and promote blended learning, as well as to draw attention to the unequal effects on different vulnerable groups of students of inadequately provisioned online education, especially to issues of digital poverty and the inequitable impact which not addressing this adequately will have in the future. For teachers' learning and professional development, this has largely meant that many of their urgent needs were met with selective and partially adequate measures that did not fully address the unfolding challenges of remote teaching that they were faced with.

\section{References}

Aguilera, E., Nightingale-Lee, B. (2020). Emergency remote teaching across urban and rural contexts: perspectives on educational equity. Information and Learning Sciences, Epub ahead of print 29 June 2020. DOI: $10.1108 /$ ILS-04-2020-0100.

Carrillo, C., Flores, M.A. (2020). COVID-19 and teacher education: a literature review of online teaching and learning practices. European Journal of Teacher Education. 43(4): 466-487. DOI: 10.1080/02619768.2020.1821184.

Ching, Y-H., Hsu, Y-C., \& Baldwin, S. (2018). Becoming an online teacher: an analysis of prospective online instructors' reflections. Journal of Interactive Learning Research. 29(2): 145168. https://doi.org/10.24059/olj.v22i2.1212.

Di Pietro, G., Biagi, F., Costa, P., Karpiński, Z. \& Mazza, J. (2020). The likely impact of COVID-19 on education: Reflections based on the existing literature and recent international datasets. Luxembourg: Publications Office of the European Union. DOI:10.2760/126686, JRC121071.

Dombos, T., Krizsan, A., Verloo, M., \& Zentai, V. (2012). Critical Frame Analysis: A Comparative Methodology for the QUING Project. Working Paper Series, Center for Policy Studies. Central European University. Hungary: 
Budapest. $\quad$ http://pdc.ceu.hu/archive/00006845/01/cps-working-paper-critical-frame-analysis-quing2012.pdf [downloaded April 2020].

Hodges, C., Moore, S., Lockee, B., Trust, T., \& Bond, A. (2020). The difference between emergency remote teaching and online learning. In: EDUCAUSE Review. Available at: https://er.educause.edu/articles/2020/3/the-difference-between-emergency-remote-teaching-andonline-learning (accessed 9th of November).

Holotescu, C., Grosseck, G., Andone, D., Gunesch, L., Costandache, L., Nedelcu, V.D., Ivanova, M., \& Dumbrăveanu, R. (2020). Romanian education system response during the COVID-19 pandemic. Proceedings of the 16th International Scientific Conference "eLearning and Software for Education",Bucharest, April 23-24, 2020, pp. 11- 20. DOI: 10.12753/2066-026X-20-171.

Kerres, M. (2020). Against All Odds: Education in Germany Coping with Covid-19. Postdigital Science Education (2): 690-694.https://doi.org/10.1007/s42438-020-00130-7.

König, J., Jäger-Biela, D.J. and Glutsch, N. (2020). Adapting to online teaching during COVID-19 school closure: teacher education and teacher competence effects among early career teachers in Germany. European Journal of Teacher Education. 43 (4): 608-622, DOI: 10.1080/02619768.2020.1809650.

OECD.(2019). PISA 2018 Results (Volume II): Where All Students Can Succeed. Paris: OECD Publishing. https://doi.org/10.1787/b5fd1b8f-en.

Rapanta, C., Botturi, L., Goodyear, P., Guardia, L., Koole, M. (2020). Online University Teaching During and After the Covid-19 Crisis: Refocusing Teacher Presence and Learning Activity. Postdigital Science Education. (2): 923-945. https://doi.org/10.1007/s42438-020-00155-y.

Reimers, F.M, Schleicher, A. (2020). Education responses to COVID-19: Embracing Digital Learning and Online Collaboration [OECD report]. https://bit.ly/39hDURb.

Scull, J., Phillips, M., Sharma, U. , \& Garnier, K. (2020) Innovations in teacher education at the time of COVID19: an Australian perspective. Journal of Education for Teaching. DOI: 10.1080/02607476.2020.1802701.

Shulman, L. S. (1987). Knowledge and Teaching. Foundations of the New Reform. Harvard Educational Review. (57): 1-22. DOI:10.17763/haer.57.1.j463w79r56455411.

Van Lancker, W., Parolin, Z. (2020). COVID-19, school closures, and child poverty: a social crisis in the making. The Lancet Public Health. 5(5): E243-E244. https://doi.org/10.1016/S2468-2667(20)30084-0.

Verloo, M. (2005). Displacement and empowerment: Reflections on the Concept and Practice of the Council of Europe Approach to Gender Mainstreaming and Gender Equality. Social Politics. 12(3): 344-365 